\title{
Organ-Specific Disposition of Group B Streptococci in Piglets: Evidence for a Direct Interaction with Target Cells in the Pulmonary Circulation
}

\author{
BRUCE D. BOWDY, SCHEWAN M. AZIZ, STEPHEN L. MARPLE, KOKICHI YONEDA, \\ THOMAS H. PAULY, J. DONALD COONROD, AND MARK N. GILLESPIE \\ University of Kentucky A.B. Chandler Medical Center, College of Pharmacy, Division of Pharmacology and \\ Experimental Therapeutics, and College of Medicine, Departments of Medicine, Pediatrics, and Pathology, and \\ the Veterans Administration Hospital, Lexington, Kentucky 40536
}

\begin{abstract}
Despite the serious pulmonary manifestations of early onset group B streptococcal (GBS) sepsis, it is not known whether the organism distributes into lung tissue and whether adverse pulmonary hemodynamic abnormalities relate to an interaction between the organism and target cells in the pulmonary vascular bed. Accordingly, this study evaluated the distribution and fate of GBS in the lung, liver, and spleen of anesthetized infant piglets and in isolated, salt solution-perfused piglet lung preparations. GBS were radiolabeled with ${ }^{11}$ Indium-oxine and infused at a dose of $10^{8} \mathrm{organisms} / \mathrm{kg} / \mathrm{min}$ for $15 \mathrm{~min}$ into anesthetized piglets ranging in age from 5-10 d. Forty-five min after termination of the infusion, animals were killed and specimens of lung, liver, spleen, and blood were excised and the relative deposition and viability of GBS were determined. Most of the recovered bacteria were detected in the lung $(53.2 \pm 3.9 \%)$ followed by the liver $(41.4 \pm$ $2.0 \%)$ and spleen $(2.2 \pm 0.38 \%)$. GBS detected in the blood was estimated to be only $3.2 \pm 1.0 \%$ of the infused dose. Viability of GBS was least in the lung $(21.4 \pm 2.6 \%)$ relative to the liver $(45.7 \pm 11.2 \%)$ and spleen $(83.4 \pm$ $19.5 \%$ ). After a 60 -min GBS infusion, transmission electron microscopy localized the organism within pulmonary intravascular macrophages in the lung; there was no evidence for bacterial interaction with either neutrophils or endothelial cells. In the liver, GBS was found exclusively in Kupffer cells. In isolated piglet lungs perfused at a constant flow rate with blood-free physiologic salt solution, GBS $\left(10^{6}\right.$ to $10^{8}$ organisms $\left./ \mathrm{mL}\right)$ provoked concentrationdependent increases in pulmonary vascular resistance. Transmission electron microscopic examination of isolated lungs indicated that GBS was localized within pulmonary intravascular macrophages, again with no apparent intractions between the organism and other cellular residents of the pulmonary vascular bed. These results indicate that GBS distributes into lung and liver where resident intravascular phagocytes, possibly pulmonary intravascular macrophages and Kupffer cells, respectively, contribute to killing of the organism. In addition, because GBS evokes pulmonary hypertension in isolated piglet lung preparations, it appears that cardiopulmonary disturbances in the
\end{abstract}

Received June 8, 1989; accepted November 17, 1989.

Correspondence and reprint requests: Mark N. Gillespie, Ph.D., University of Kentucky, College of Pharmacy, Division of Pharmacology and Toxicology, Lexington, KY 40536.

Supported in part by grants from the National Institutes of Health (HL-36404, HL-38495, and an RCDA to M.N.G., HL-02055), the Cystic Fibrosis Foundation, the Kentucky Affiliate of the American Heart Association, and the Veterans Administration. intact animal could be initiated by a direct interaction between GBS and resident lung cells without obligatory participation by other organ systems. (Pediatr Res 27: 344-348, 1990)

\section{Abbreviations}

GBS, group B streptococcus

HBSS, Hanks' balanced salt solution

cfu, colony-forming unit

Ppa, pulmonary arterial pressure

Pla, left atrial pressure

Rt, total resistance

$\mathrm{Ra}$, arterial resistance

$R v$, venous resistance

Pdo, double occlusion pressure

The question is straight-forward: Does GBS promote pulmonary hypertension in the newborn through interaction with a target cell in the lung? The concept that GBS-induced pulmonary hypertension results from an interaction with resident lung cells is intuitively appealing. The lung contains several cell types that could serve as transducers of the pulmonary hemodynamic response to GBS. For example, the lung contains a substantial population of marginated neutrophils, a phagocytic cell known to elaborate various mediators incriminated in the response to GBS (1), including thromboxane $\mathrm{A}_{2}$, sulfidopeptide leukotrienes, and toxic oxygen radicals (2-4). Pulmonary vascular endothelial cells also exhibit phagocytic activity $(5,6)$ and produce eicosanoids with chemoattractant activity for neutrophils (7). The pulmonary microcirculation also is the site of a recently discovered population of intravascular macrophages that function to clear circulating bacteria and inert particulates from the blood during pulmonary transit (8). Significantly, these cells, too, generate vasoactive and injurious metabolites of arachidonic acid (9) and, in adult sheep, seem to play a central role in initiating the adverse pulmonary hemodynamic consequences of microembolization with liposomes (10). However, the liver is traditionally viewed as the predominant reticuloendothelial organ of the body. Activated hepatic macrophages, so-called Kupffer cells, release a battery of vasoactive and injurious mediators, including thromboxane $\mathrm{A}_{2}$, sulfidopeptide leukotrienes, and oxygen radicals along with the cytokines interleukin 1 and tumor necrosis factor (11-13). Consequently, it seems plausible that GBS, through deposition in the liver, could promote release into the circulation of factors that incite the pulmonary vascular response. 
Our study had several principal goals. First, we sought to quantitate the distribution and killing of GBS in the classic reticuloendothelial organs, the liver and spleen, and compare these with clearance of GBS into the lung. Second, we hoped to identify the cell types in which GBS could be localized in these organs. Finally, we used isolated piglet lung preparations perfused with blood-free salt solution to determine if pulmonary hypertension could be initiated via a direct interaction between GBS and target cells in the lung.

\section{MATERIALS AND METHODS}

Preparation of ${ }^{111}$ In-labeled GBS and assessment of bacterial disposition. Cultures of GBS (Streptococcus agalacticae, serotype II, American Type Culture Collection no. 13813, Difco Laboratories, Detroit, MI) were inoculated in brain-heart infusion broth containing 7\% heat-inactivated FCS and grown to log phase at $37^{\circ} \mathrm{C}$ under a $5 \% \mathrm{CO}_{2}$ atmosphere. The medium was centrifuged at $2000 \times g$ for $15 \mathrm{~min}$ and the pellet washed and resuspended in HBSS. Concentration of bacteria in the slurry was determined by quantitative culture and by relating optical density to cfu. To assess deposition of GBS, the organisms were radiolabeled with ${ }^{11}$ Indium-oxine using the following procedure: GBS suspended in HBSS were centrifuged, the pellet was resuspended in HBSS, and $1 \mathrm{~mL}$ containing approximately $2.5 \times 10^{10} \mathrm{cfu}$ was transferred to a microfuge tube and mixed with $15 \mu \mathrm{Ci}{ }^{111}$ In-oxine. The tube was vortexed three times at 5-min intervals and then centrifuged at $15000 \times g$ for $2 \mathrm{~min}$. The resulting pellet was resuspended in $1 \mathrm{~mL}$ HBSS. This procedure (vortexing, centrifugation, and resuspension) was repeated four times. After the third cycle, bacteria were resuspended in $50 \mathrm{~mL}$ of medium (instead of $1 \mathrm{~mL}$ ) and allowed to stand at room temperature for $1.5 \mathrm{~h}$ to remove any remaining soluble or loosely adherent indium. After the last centrifugation, the pellet was resuspended in HBSS to a bacterial concentration $10^{9} \mathrm{cfu} / \mathrm{mL}$. Thorough preliminary experiments demonstrated that neither the sp act the radiolabeled bacteria nor bacterial viability changed as a function of time after the labeling procedure and that only $10 \%$ or less of the total radioactivity was present in the infusate as unbound label.

Piglets ranging in age from $5-10 \mathrm{~d}$ and in wt from $1.9-2.8 \mathrm{~kg}$ were anesthetized with $50 \mathrm{mg} / \mathrm{kg}$ sodium pentobarbital (i.p.) and placed on a servo-controlled heat exchanging pad to maintain body temperature at $38 \pm 1{ }^{\circ} \mathrm{C}$. A tracheal cannula was inserted and the animals were ventilated $\left(\mathrm{FIO}_{2}=0.3\right)$ with a Harvard small animal ventilator (Kent, England). A polyethylene catheter was inserted into the jugular vein and advanced into the pulmonary artery for monitoring of Ppa. Additional catheters were inserted into the femoral vein and artery for bacterial administration and for monitoring of $\mathrm{Ppa}$ and systemic arterial pressures. Pressures were monitored using Statham transducers (Oxnard, $\mathrm{CA}$ ) in conjunction with a Grass model 7 polygraph (Quincy, MA). Arterial blood gases in 1-mL blood samples taken from the arterial catheter were determined using an Instrument Laboratories model 213 blood gas analyzer (Lexington, MA). During a 30 -min equilibration period, the ventilator was adjusted to attain $\mathrm{PO}_{2}, \mathrm{PCO}_{2}$, and $\mathrm{pH}$ values of 100 torr, 40 torr, and 7.4, respectively.

Animals were killed with an overdose of sodium pentobarbital at 45 min after termination of a $15-\mathrm{min}$ infusion of $10^{8} \mathrm{cfu}$ GBS/ $\mathrm{kg} / \mathrm{min}$. The lungs, liver, and spleen were removed aseptically, weighed, and homogenized in $4 \mathrm{~mL}$ sterile HBSS. Radioactivity was determined in an aliquot of homogenate using a Packard gamma counter (Downers Grove, IL). Bacterial deposition was quantitated as the percentage of radioactivity distributing into a particular organ relative to the total amount recovered. To assess the amount of bacteria remaining in the blood, a $1-\mathrm{mL}$ blood sample was taken at the time organs were removed and reserved for determination of radioactivity. The blood vol was estimated as $80 \mathrm{~mL} / \mathrm{kg}$ body wt and multiplied by the radioactivity deter- mined in the $1-\mathrm{mL}$ reference sample. The amount of bacteria remaining in the estimated total blood vol expressed as a percentage of the total amount recovered. To assess bacterial viability, an aliquot of homogenate was serially diluted in HBSS, streaked on blood agar plates, and incubated for 24-48 h in 5\% $\mathrm{CO}_{2}$ at $37^{\circ} \mathrm{C}$. Bacterial colonies were counted and expressed as cfu per $\mathrm{g}$ of tissue. The percentage bacterial viability, determined according to methods previously described by Coonrod et al. (14), was calculated as: $100 \times\left[\left(\mathrm{cfu}_{\mathrm{t}} / \mathrm{cpm}_{\mathrm{t}}\right) \div\left(\mathrm{cfu}_{\mathrm{i}} / \mathrm{cpm}_{\mathrm{i}}\right)\right]$ where $\mathrm{t}$ refers to time after infusion and $\mathrm{i}$ refers to the value for the uninfused GBS inoculum. This method permits estimation of the proportion of bacteria deposited which remain viable.

Electron microscopy. Transmission electron microscopic examination was performed on lungs and liver from two pentobarbital-anesthetized piglets infused with bacteria $\left(10^{8} \mathrm{cfu} / \mathrm{kg} / \mathrm{min}\right)$ for either 15 or $60 \mathrm{~min}$ and in isolated lungs receiving bacterial challenges as described below. Lungs were infused via the airways for 30-45 min with 3\% glutaraldehyde in Sorenson's phosphate buffer ( $\mathrm{pH} 7.4$ ) at a hydrostatic pressure of $25 \mathrm{~cm} \mathrm{H}_{2} \mathrm{O}$. Lung tissue samples were taken from the lower left lobe and, along with specimens of liver, were immersed in fresh Sorenson's buffer for an additional $24 \mathrm{~h}$. Subsequently, tissue was transferred to $0.2 \mathrm{M}$ cacodylate buffer containing $2 \%$ sucrose. For transmission electron microscopy, tissue blocks 1 - to $2-\mathrm{mm}$ thick were postfixed in $1 \%$ osmium tetroxide in $0.1 \mathrm{M}$ cacodylate buffer for 2 $\mathrm{h}$ and stained en bloc with $0.5 \%$ uranyl acetate at pH 5.0. Samples were then dehydrated in graded alcohols and propylene oxide, embedded in epoxy resins, and 40- to 60-nm thick sections were cut with a diamond knife using a Sorval MT2B ultramicrotome (Wilmington, DE). Sections were poststained with lead acetate and examined on a Phillips 300 electron microscope (Mahwah, $\mathrm{NJ})$.

Isolated, perfused piglet lung preparation. Piglets ranging in age and wt from $1.7-2.5 \mathrm{~kg}$ and $3-10 \mathrm{~d}$, respectively, were anesthetized with sodium pentobarbital $(50 \mathrm{mg} / \mathrm{kg}$, intraperitoneally). The trachea was cannulated and the animals were ventilated with room air at a tidal volume of $7 \mathrm{~mL} / \mathrm{kg}$ and at a rate of 45 breaths/min. The thorax was opened and the animals received an intraventricular injection of $400 \mathrm{U}$ heparin $/ \mathrm{kg}$. Subsequently, the pulmonary artery and left atrium were cannulated and the pulmonary circulation was perfused at $20 \mathrm{~mL} / \mathrm{min}$ with $500 \mathrm{~mL}$ of warmed $\left(37^{\circ} \mathrm{C}\right)$, physiologic salt solution in a nonrecirculation manner to wash residual blood elements from the lung. The composition of the physiologic salt solution in $\mathrm{mM} / \mathrm{L}$ was: $\mathrm{NaCl}, 118 ; \mathrm{KCl}, 4.7 ; \mathrm{CaCl}_{2}, 1.9 ; \mathrm{MgSO}_{4}, 0.57 ; \mathrm{KH}_{2} \mathrm{PO}_{4}$, 1.18; $\mathrm{NaH}_{2} \mathrm{CO}_{3}, 24.9$; dextrose, 6.0 ; and BSA, $3 \%$ (wt/vol). All chemicals were of reagent grade and were dissolved in distilled, deionized water.

After perfusing the pulmonary circulation in a nonrecirculating manner, the heart and lungs were excised en bloc and suspended in a warmed $\left(37^{\circ} \mathrm{C}\right)$, humidified "thorax." Perfusion was changed from nonrecirculating to the recirculating mode with $400 \mathrm{~mL}$ perfusion medium in the reservoir and the perfusion rate adjusted to $30 \mathrm{~mL} / \mathrm{min} / \mathrm{kg}$ body wt of the donor animal. Ventilation was then switched to $95 \%$ air supplemented with $5 \%$ $\mathrm{CO}_{2}$. Positive end-expiratory pressure $\left(4 \mathrm{~cm} \mathrm{H}_{2} \mathrm{O}\right)$ was then applied and the preparation was allowed to equilibrate for 20 min. Baseline $\mathrm{PO}_{2}, \mathrm{PCO}_{2}$, and $\mathrm{pH}$ in this isolated system were $125 \pm 2.4,44.5 \pm 2.3$, and $7.4 \pm 0.04$, respectively. Ppa and Pla were measured from transducers zeroed at the level of the heart. Pdo was measured by transiently interrupting flow through the pulmonary circulation and allowing pressure to equilibrate over the entire vascular bed. Pdo has been shown to be an indirect but reliable estimate of pulmonary microvascular pressure (15). Pressures were recorded on a Grass model 79 polygraph. Resistance across the Rt vascular bed along with the $\mathrm{Ra}$ and $\mathrm{Rv}$ components of the pulmonary vascular resistance were calculated in the following manner:

$$
\begin{aligned}
\mathrm{Rt} & =(\mathrm{Ppa}-\mathrm{Pla}) /(\mathrm{Q} / \mathrm{kg}) \\
\mathrm{Ra} & =(\mathrm{Ppa}-\mathrm{Pdo}) /(\mathrm{Q} / \mathrm{kg}) \\
\mathrm{Rv} & =(\mathrm{Pdo}-\mathrm{Pla}) /(\mathrm{Q} / \mathrm{kg})
\end{aligned}
$$


The term $\mathrm{Q}$ in the equations refers to the flow rate, which was held constant at $30 \mathrm{~mL} / \mathrm{min} / \mathrm{kg}$ body wt of the donor animal.

Four isolated lungs were challenged with GBS by sequential addition of the organisms to the perfusate reservoir in concentrations of $10^{6}, 10^{7}$, and $10^{8} \mathrm{cfu} / \mathrm{mL}$. Peak changes in vascular pressures occurred within 4-6 min of bacterial challenge. Preparations received the next highest bacterial dose at 8-10 min after the preceding challenge. Ten min after receiving the $10^{8}$ $\mathrm{cfu} / \mathrm{mL}$ bacterial dose, two isolated lungs were prepared for electron microscopic assessment of bacterial localization as described above.

Statistical analysis. Differences in the relative distributions in GBS between the lung, liver, spleen, and blood were assessed using a one-way analysis of variance and Neumann-Keuls test for multiple comparisons, as appropriate. The impact of selected concentrations of GBS on vascular resistances in isolated, perfused lung preparations was evaluated using a one-way analysis of variance and Neumann-Keuls test for multiple comparisons when appropriate. $p$ values $\leq 0.05$ were considered to denote statistical significance.

\section{RESULTS}

Pulmonary hemodynamic effects of $G B S$. A 15-min i.v. infusion of GBS $\left(10^{8} \mathrm{cfu} / \mathrm{min}\right)$ increased mean pulmonary arterial pressure by $18.6 \pm 2.2$ torr. Arterial $\mathrm{Po}_{2}$ decreased by $25.6 \pm 9.0$ torr. These changes reverted to control levels within $5-10 \mathrm{~min}$ of termination of the GBS infusion.

Organ-specific disposition of GBS. Figure 1 illustrates the relative distribution and viability of ${ }^{111}$ In-labeled GBS into lung, liver, spleen, and blood. GBS was administered as a 15-min i.v. infusion of $10^{8}$ organisms $/ \mathrm{kg} / \mathrm{min}$ and bacterial disposition was assessed $45 \mathrm{~min}$ after termination of the infusion. Deposition was greatest in lung and liver followed by the spleen. The total blood volume also contained a minute quantity of infused bacteria. Bacterial viability was least in the lung, significantly greater in the liver, and nearly $100 \%$ in the spleen.

Transmission electron microscopy was used to determine the cell type in which bacteria localized in the lung and liver. The spleen was not examined because this organ did not appear to contribute significantly to clearance of GBS. Bacterial deposition initially was examined after a $15-\mathrm{min}$ GBS infusion $\left(10^{8} \mathrm{cfu} / \mathrm{kg} /\right.$ min). However, because very few bacteria were detected by electron microscopy using this protocol, additional experiments were conducted using a 60 -min infusion of GBS given at the same dose rate. In these studies, bacteria were readily detected in both lung and liver. As illustrated in Figure 2, bacteria in the lung were localized to pulmonary intravascular macrophages. We found no evidence for localization of GBS within endothelial cells or sequestered leukocytes. In the liver (Fig. 3), GBS were localized exclusively within Kupffer cells.

Effects and localization of $G B S$ in isolated piglet lungs. Studies

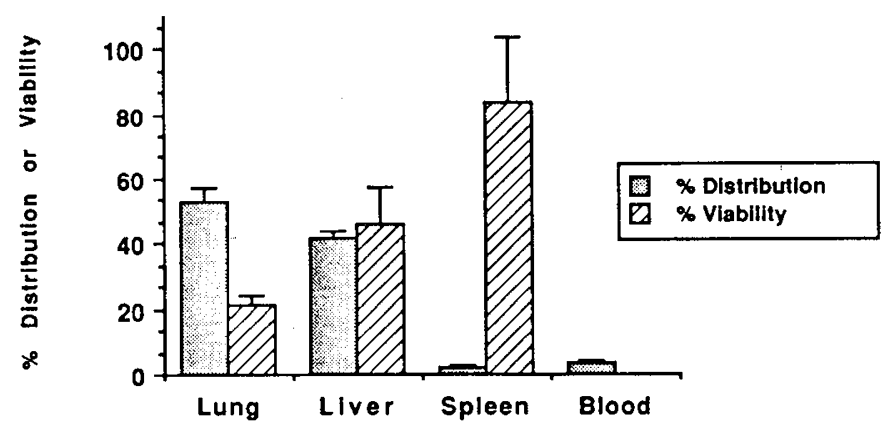

Fig. 1. Percentage distribution of ${ }^{11}$ indium (solid bars) and percentage of GBS remaining viable (hatched bars) in lung, liver, spleen, and blood in anesthetized piglets $(n=11)$. GBS were given as a 15 -min infusion of $10^{8} \mathrm{cfu} / \mathrm{kg} / \mathrm{min}$ and distribution and viability of the organism was determined $45 \mathrm{~min}$ later.

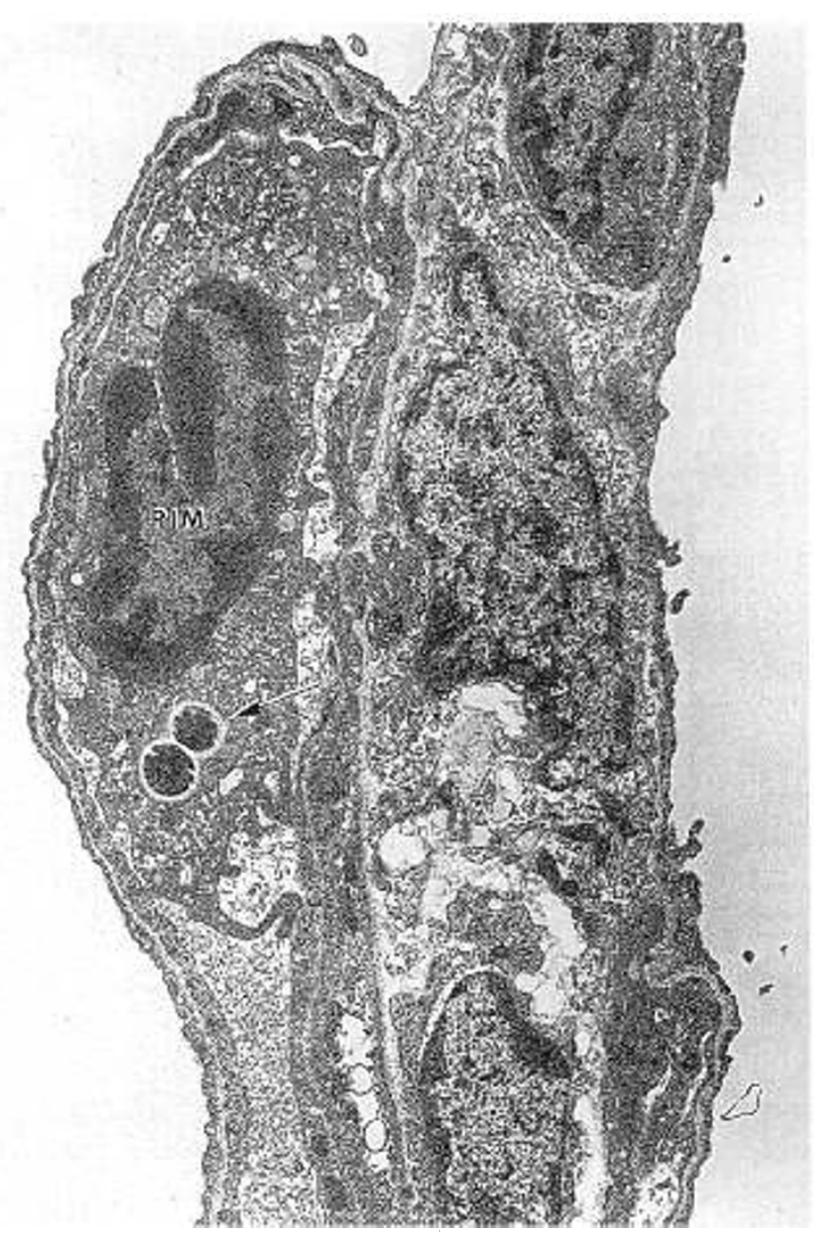

Fig. 2. Transmission electron micrograph demonstrating localization of GBS (arrow) within a pulmonary intravascular macrophage $(P I M)$ in an intact, anesthetized piglet. Magnification $\times 13000$.

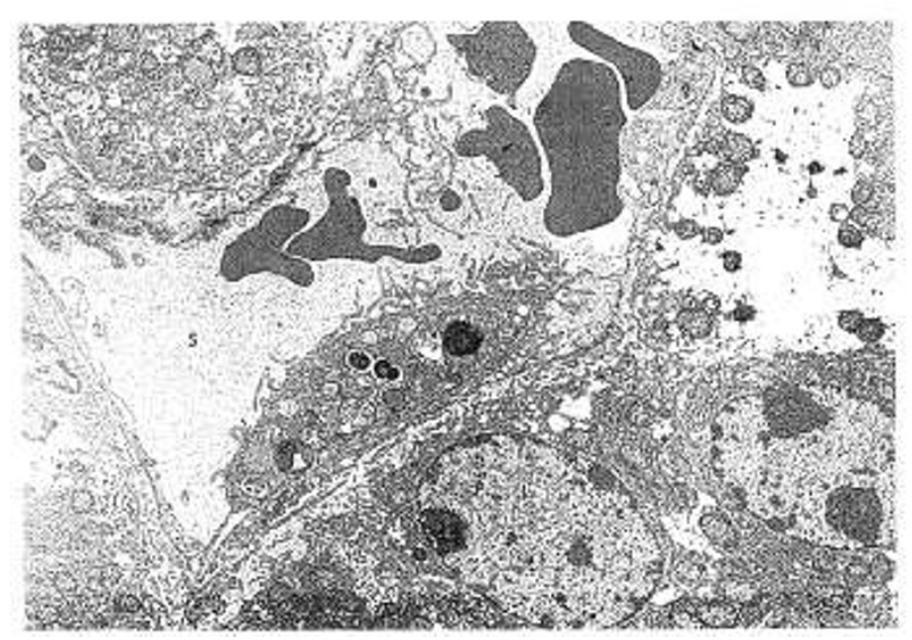

Fig. 3. Transmission electron micrograph demonstrating localization of GBS within a hepatic Kupffer $(K)$ cell in an intact, anesthetized piglet. $S$, sinusoid, $L$, liver cell. Magnification $\times 5900$.

were conducted in isolated piglet lung preparations to determine if GBS in concentrations of $10^{6}-10^{8} \mathrm{cfu} / \mathrm{mL}$ of perfusion medium caused pulmonary hypertension without involvement of other organ systems. As shown in Figure 4, GBS caused concentration-dependent increases in $\mathrm{Rt}$ and its components, $\mathrm{Ra}$ and $\mathrm{Rv}$. Increases in $\mathrm{Rt}$ were related principally to elevations in $\mathrm{Ra}$ with only a modest contribution of increases in Rv. At the end of the lung perfusion protocol, isolated lungs were prepared for 


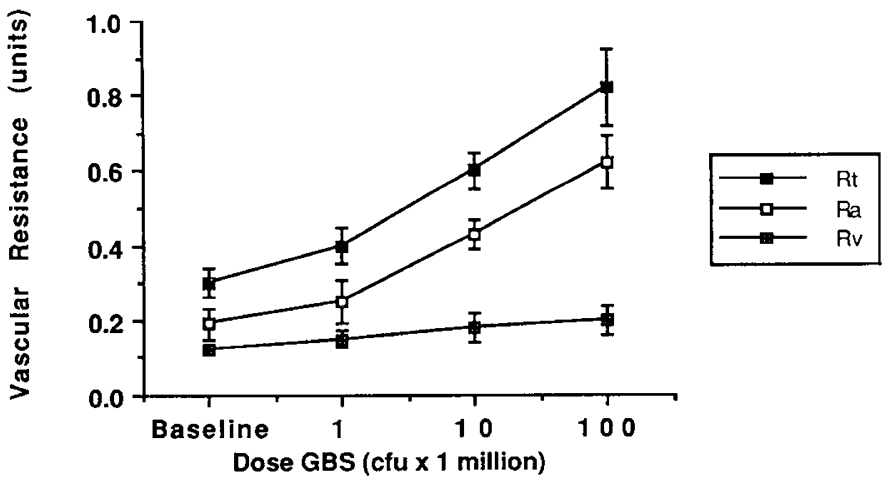

Fig. 4. Concentration-dependent effects of GBS on Rt, Ra, and Rv resistances in isolated piglet lungs perfused at constant flow with bloodfree Krebs-Henseleit medium $(n=4)$.

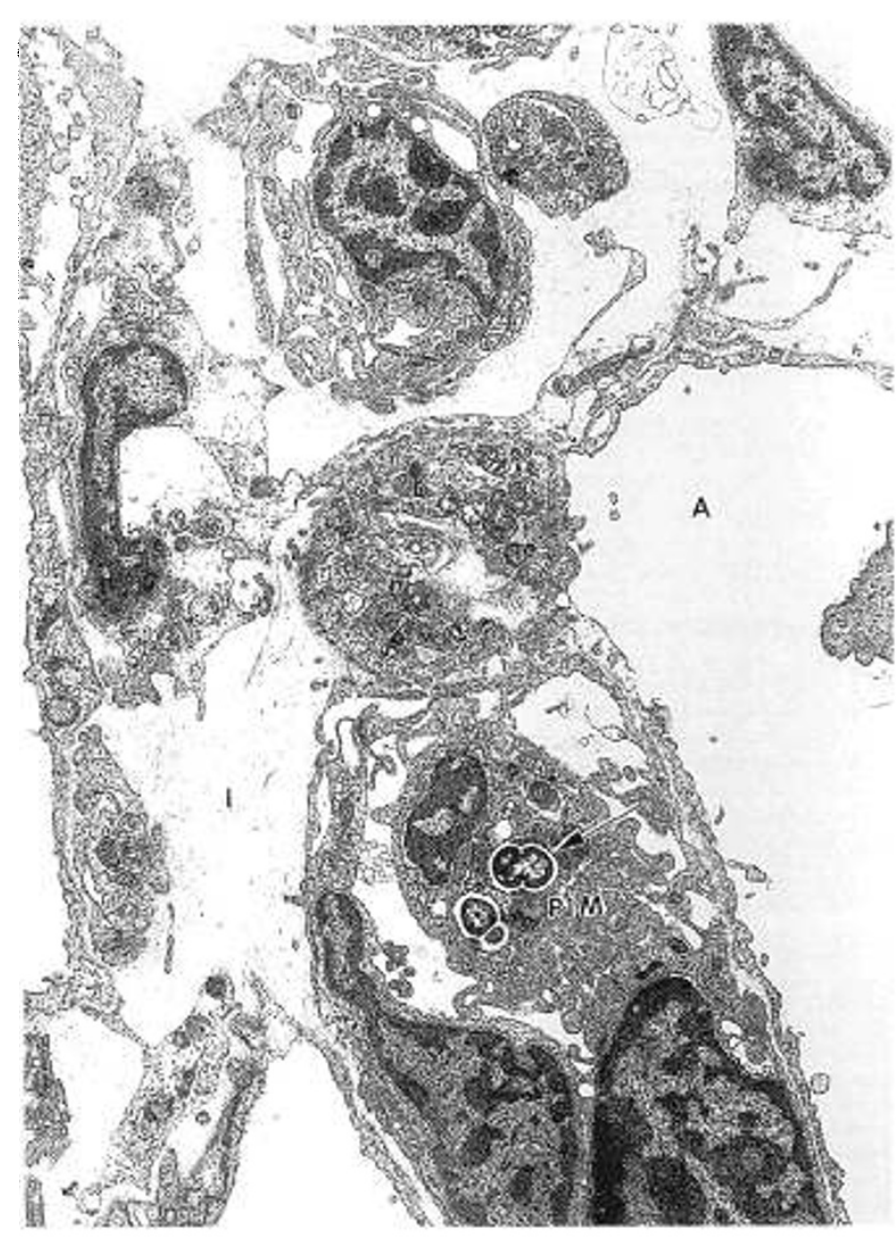

Fig. 5. Transmission electron micrograph demonstrating localization of GBS (arrow) within a pulmonary intravascular macrophage (PIM) after intravascular delivery to an isolated piglet lung perfused at constant flow rate with blood-free Krebs-Henseleit solution. $I$, interstitium; $A$, alveolus. Magnification $\times 8700$.

electron microscopic examination. Similar to the results in intact animals, GBS administered to isolated lungs were localized in pulmonary intravascular macrophages (Fig. 5). Bacterial uptake by endothelial cells or sequestered neutrophils was not observed. Interestingly, bacteria also were noted in the airways of perfused lungs, in contrast to their confinement to the vascular compartment in intact piglets. Also in contrast to observations in intact animals, perivascular edema was evident in isolated lungs receiving GBS.

\section{DISCUSSION}

In our experiments, as in numerous previous publications, GBS produced pulmonary hypertension accompanied by arterial hypoxemia. A number of chemical mediators have been incriminated in the pulmonary response to GBS sepsis, including thromboxane $\mathrm{A}_{2}$ (2) sulfidopeptide leukotrienes (3) and toxic oxygen radicals (4). Based on their involvement in animal models of endotoxin-induced lung injury, it is possible that the cytokines tumor necrosis factor and IL-1 also contribute to GBS-induced pulmonary abnormalities $(16,17)$. Despite the relatively detailed information concerning the pathophysiologic characteristics and chemical mediators of GBS-induced pulmonary hypertension, it is not known whether GBS interacts with a target cell population in the lung to initiate the hypertensive response or whether involvement of other organs is required. In this context, there are at least several itinerant or resident lung cell types, including pulmonary intravascular macrophages, endothelial cells, or neutrophils, which could phagocytose intravascular GBS and which elaborate the above mentioned autacoids (4-8). The liver, a classic component of the reticuloendothelial system, also contains resident phagocytes known to release some of these chemical mediators into the circulation (11-13). Against this background, our study sought to determine if GBS distributed into the lung and if pulmonary hypertension was initiated through an interaction with a resident lung cell population or if other organs, particularly the liver, were essential for development of hemodynamic abnormalities.

We found that infused GBS distributed to similar extents into the lungs and liver of infant piglets. That the lung, in addition to the liver, is important to clearance of intravascular particulates is consistent with a number of previous reports on organ-specific distribution of bacteria and particulates in adult pigs (8). However, most previous studies indicate that, in the specific case of pigs, distribution into the lung is relatively greater than that in liver or spleen. The reasons for such a quantitative difference between the present experiments and earlier reports are not clear, but at least two major factors may contribute. First, it is known that organ distribution depends somewhat on the type of bacteria. Rogers noted in rabbits that although Staphylococci localized principally in circulating neutrophils, Escherichia coli and Pseudomonas distributed into the liver (18). A second reason relates to the age of the animals. Previous reports have used adult pigs, whereas the present experiments used animals between 5 and 10 $\mathrm{d}$ old. There are multiple differences in host-defense mechanisms between adults and infants that might influence bacterial disposition, including a decreased density of pulmonary intravascular macrophages in neonates (19) and depressed capacities of other phagocytes such as neutrophils (20). Regardless of the mechanism underlying quantitative differences between the organspecific disposition of GBS in infant piglets and other bacteria in adult pigs, the fact that GBS distributes into the lung and liver suggests that both organs could affect the pulmonary hemodynamic response to GBS.

Early studies on organ-specific bacterial disposition used quantitative culture techniques to assess bacterial clearance. However, this approach fails to discriminate between clearance due to deposition and clearance due to killing. In our study we found that substantial proportions of bacteria distributing into the lungs and liver were killed. This observation is consistent with a preliminary report from our laboratory indicating that the lung kills GBS in part through an oxygen radical-dependent bactericidal mechanism and that oxygen radical-dependent bacterial killing may be functionally linked to development of hemodynamic abnormalities (21).

The cell types in the lung and liver responsible for bacterial killing GBS have not been previously reported. In our experiments, electron microscopy localized GBS in the lung to pulmonary intravascular macrophages and, in the liver, to Kupffer cells. Although the bactericidal capacity of pulmonary intravas- 
cular macrophages has yet to be assessed, Kupffer cells, their morphologic counterpart, are known to exhibit such activity (22). Interactions between GBS and neutrophils or endothelial cells were not observed in either organ. Based on these considerations, we suggest that pulmonary intravascular macrophages and Kupffer cells play central roles in host-defense against GBS in infant piglets. Nevertheless, certain limitations of our experimental design dictate that this suggestion be viewed with caution. By necessity, our microscopic analysis was performed on piglets receiving bacterial infusions for $60 \mathrm{~min}$, whereas bacterial deposition and viability were evaluated in a separate group of animals at 45 min after termination of a 15 -min bacterial infusion. The two groups of animals thus received bacteria administered by different dosing regimens which, in turn, could conceivably influence the pattern of cellular localization. Perhaps more importantly, our electron microscopic analysis was qualitative and performed on only a few subjects. Important interactions between GBS and other cells could have been overlooked.

The foregoing observations indicated that GBS distributes into the lung and liver and evokes a microbicidal response in these organs. Further, the cells that appear to be responsible for the bactericidal activity are believed to be metabolically active and capable of releasing a variety of vasoactive and injurious mediators implicated in GBS sepsis. Thus, bacterial interaction with cells in either or both organs could elaborate mediators that initiate pulmonary hypertension. We reasoned that a most direct means to determine if bacterial uptake into resident lung cells was sufficient to initiate pulmonary hypertension was to use an isolated lung preparation. If GBS promoted hypertension in the isolated lung and if the bacteria were localized in the same cell type with which it interacted in the intact animal, this would constitute provocative evidence for a direct interaction with target cells of the lung. Using an isolated piglet lung preparation perfused with blood-free medium, we found that GBS promoted concentration-dependent increases in $\mathrm{Rt}$ that were attributed primarily to elevations in $\mathrm{Ra}$. Consistent with the above observations in intact animals, electron microscopic examination of isolated lungs perfused with GBS indicated bacterial uptake by pulmonary intravascular macrophages with no evidence for interactions with endothelial cells or sequestered neutrophils. Perivascular "cuffs" suggestive of edema formation also were noted and are consistent with the GBS-induced pulmonary edema formation in intact animals (4). These observations are interesting on two accounts. First, they indicate that pulmonary hypertension in response to GBS can be initiated by an interaction between the bacteria and resident pulmonary vascular cells without the obligatory participation of organ systems other than the lung. Second, keeping in mind the limitations of our electron microscopic analysis noted above, because bacteria were localized within pulmonary intravascular macrophages and because no evidence for interactions between bacteria and neutrophils were noted, it is tempting to speculate that intravascular macrophages were important in initiating the hypertensive response. Interestingly, granulocyte depletion with hydroxyurea blocks the pulmonary hemodynamic response to GBS in young lambs (22), thus suggesting that neutrophils do indeed have an important role in this model of sepsis-induced lung injury. Based on these considerations, it seems likely that pulmonary intravascular macrophages interact with other lung cells, including neutrophils and perhaps endothelial cells, to promote the constellation of pulmonary abnormalities associated with GBS sepsis.

In summary, results of this study indicate that in piglets, GBS is taken up and killed by the liver and lung. The cell types responsible for microbicidal activity may be the hepatic Kupffer cell and the pulmonary intravascular macrophage, respectively. GBS administered to isolated piglet lungs perfused with bloodfree medium is localized in pulmonary intravascular macrophages and causes pulmonary hypertension. These observations suggest that GBS may promote pulmonary hypertension through a direct interaction with resident lung cells and without obligatory participation of organs other than the lung.

Acknowledgement. The authors are indebted to Dr. Carol A. Baker for determining the serotype of the commercially-available GBS used in our studies.

\section{REFERENCES}

1. Hogg JC 1987 Neutrophil kinetics and lung injury. Physiol Rev 67:1249-1295

2. Runkle B, Goldberg RN, Streitfeld MM, Clark MR, Buron E, Setzer ES Bancalari E 1984 Cardiovascular changes in group B streptococcal sepsis: relationship to prostacyclin and thromboxane $\mathrm{A}_{2}$. Pediatr Res 18:874-878

3. Goldberg RN, Suguihara C, Streitfeld MM, Bancalari A, Clark MR, Bancalari E 1986 Effects of a leukotriene antagonist on the early hemodynamic manifestations of group B streptococcal sepsis in piglets. Pediatr Res 20:1004-1008

4. Pauly TH, Bowdy BD, Haven CA, Barr SB, Gillespie MN 1988 Evidence for hydroxyl radical involvement in group $B$ streptococcus-induced pulmonary hypertension and arterial hypoxemia in young piglets. Pediatr Res 24:739745

5. Vann JM, Proctor RA 1987 Ingestion of Staphylococcus aureus by bovine endothelial cells results in time- and innoculum-dependent damage to endothelial cell monolayers. Infect Immun 55:2155-2163

6. Valberg PA, Meyrick B, Brain JD, Brigham KL 1988 Phagocytic and motile properties of endothelial cells measured magnetometrically: effects of endotoxin. Tissue Cell 20:345-354

7. O'Brien RF, Seton MP, Makarski JS, Center DM, Rounds S 1984 Thiourea causes endothelial cells in tissue culture to produce neutrophil chemoattractant activity. Am Rev Respir Dis 130:103-109

8. Winkler GC 1988 Pulmonary intravascular macrophages in domestic animal species: review of structural and functional properties. Am J Anat 181:217234

9. Bertram TA, Overby LH, Danilowicz R, Eling TE, Brody AR 1988 Pulmonary intravascular macrophages metabolize arachidonic acid in vitro. Am Rev Respir Dis 138:936-944

10. Miyamoto K, Shultz E, Heath T, Mitchell MD, Albertine KH, Staub NC 1988 Pulmonary intravascular macrophages and hemodynamic effects of liposomes in sheep. J Appl Physiol 64:1143-1152

11. Nathan CF 1987 Secretory products of macrophages. J Clin Invest 79:319-326

12. Keppler D, Hagmann W, Rapp S, Denzlinger C, Kocj HK 1985 The relation of leukotrienes to liver injury. Hepatology 5:883-891

13. Keller GA, West MA, Harty JT, Wilkes LA, Cerra FB, Simmons, RL 1985 Modulation of hepatic protein synthesis by endotoxin-activated Kupffer cells. III. Evidence for a role of a monokine similar to but not identical with interleukin-1. Ann Surg 201: 436-443

14. Coonrod JD, Marple S, Holmes GP, Rehm SR 1987 Extracellular killing of inhaled pneumococci in rats. J Lab Clin Med 110: 753-766

15. Townsley MI, Korthuis RJ, Rippe B, Parker JC, Taylor AE 1986 Validation of the double vascular occlusion method for $\mathrm{Pc}, \mathrm{i}$ in lung and skeletal muscle. J Appl Physiol 61:127-132

16. Beutler B, Milsark IW, Cerami A 1985 Passive immunization against cachectin/tumor necrosis factor protects mice from the lethal effect of endotoxin. Science 229:869-872

17. Cybulsky MI, McComb DJ, Movat HZ 1988 Neutrophil leukocyte emigration induced by endotoxin. Mediator roles of interleukin 1 and tumor necrosis factor $\alpha$. J Immunol 140:3144-3149

18. Rogers DE 1966 Host mechanisms which act to remove bacteria from the bloodstream. Bacteriol Rev 24:50-66

19. Winkler GC, Cheville NF 1985 Monocytic origin and postnatal mitosis of intravascular macrophages in the porcine lung. J Leukocyte Biol 38:471490

20. Lassiter HA, Christensen RD, Parker C, Rothstein G 1988 Neutrophil-mediated killing, opsonization, and serum-mediated killing of Escherichia coli $\mathrm{K} 1$ by neonatal rats. Biol Neonate $53: 156-162$

21. Bowdy BD, Marple SL, Pauly TH, Coonrod JD, Gillespie MN 1989 Oxygen radical dependent bacterial killing and pulmonary hypertension in piglets infected with group B streptococci. FASEB J 3:A903(abstr)

22. Filice GL 1988 Antimicrobial properties of Kupffer cells. Infect Immun $56: 1430-1435$

23. Englehardt B, Sandberg K, Bratton D, Van Den Abbeele A, Grogaard J, Hellerqvist C, Sundell H 1987 The role of granulocytes in the pulmonary response to group B streptococcal toxin in young lambs. Pediatr Res 21:159165 